https://helda.helsinki.fi

\title{
Pregnancy and Delivery in Women With Congenital Myopathies
}

\section{Rudnik-Schoeneborn, Sabine}

2019-04

Rudnik-Schoeneborn, S \& Wallgren-Pettersson, C 2019 , ' Pregnancy and Delivery in

Women With Congenital Myopathies ', Seminars in pediatric neurology. , vol. 29 , pp. 23-29

. https://doi.org/10.1016/j.spen.2019.01.006

http://hdl.handle.net/10138/317087

https://doi.org/10.1016/j.spen.2019.01.006

publishedVersion

Downloaded from Helda, University of Helsinki institutional repository.

This is an electronic reprint of the original article.

This reprint may differ from the original in pagination and typographic detail.

Please cite the original version. 


\title{
Pregnancy and Delivery in Women With Congenital Myopathies
}

\author{
Sabine Rudnik-Schöneborn, MD, ${ }^{*}$ and Carina Wallgren-Pettersson, $\mathrm{MD}^{\dagger}$
}

\begin{abstract}
Reports on pregnancy and delivery issues in women with congenital myopathies are scarce. In this review, we summarize the medical literature along with updates of our own data. Included are patients with nemaline myopathy $(n=11)$, central core disease $(n=6)$, multi-minicore disease $(n=2)$, cytoplasmic body myopathy $(n=1)$, and congenital fiber-type disproportion $(n=1)$. Apart from 1 patient with nemaline myopathy, who had used a wheelchair from the age of 18 years, all other women were able to walk when becoming pregnant. In comparison with the general population, there were no increased pregnancy or delivery complications, apart from the fact that $38 \%$ elective Cesarean sections took place. Neonatal outcome was favorable. In cases where a possible influence of gestation on muscle function was assessed, a deterioration during or after pregnancy was not observed. Patients who wish to have children should be advised by a multidisciplinary team according to the specific diagnosis, severity, and distribution of muscle weakness.
\end{abstract}

Semin Pediatr Neurol 29:23-29 @ 2019 Elsevier Inc. All rights reserved.

\section{Introduction}

$\mathrm{P}$ arenthood is among the highly desirable aims in life, and $P$ this also applies increasingly to women affected by rare muscle diseases. Information about the effect of the disease on the course of pregnancy and delivery and-conversely-the effect of pregnancy on muscles themselves is scarce in congenital myopathies (CM). CM comprise a genetically and clinically very heterogeneous group of muscle disorders. Over the last 20 years, the genetic basis of many different forms has been identified. It has become evident that clinically and morphologically similar phenotypes can be caused by different genotypes. Vice versa, mutations in the same gene can cause different muscle pathologies. The International Standard of Care Committee for $\mathrm{CM}^{1}$ recognizes the following major forms of $\mathrm{CM}$ which are subdivided as: nemaline myopathies, core myopathies, centronuclear myopathies, myosin storage myopathy, and congenital fiber-type disproportion.

From the *Division of Human Genetics, Medical University Innsbruck, Innsbruck, Austria.

${ }^{\dagger}$ The Folkhalsan Institute of Genetics and the Department of Medical and Clinical Genetics, Medicum, University of Helsinki, Helsinki, Finland.

Disclosure of interests: The authors have no commercial, proprietary, or financial interest in any products or companies described in this article.

Address reprint requests to Sabine Rudnik-Schöneborn, MD, Division of Human Genetics, Medical University Innsbruck, Peter-Mayr-Str. 1, 6020 Innsbruck, Austria. E-mail: sabine.rudnik@i-med.ac.at
In Northern England, the point prevalence has been estimated to be $0.2(0-0.4)$ in 100,000 for nemaline myopathy and $0.4(0.2-0.4)$ in 100,000 for central core disease. ${ }^{2}$ As each subtype of $\mathrm{CM}$ is very rare, no larger studies on reproductive issues in $\mathrm{CM}$ exist. Only case reports or smaller case series have been published, mostly without molecular genetic diagnosis. A PubMed search of all articles published in the English language with the terms "congenital myopathy," "nemaline myopathy," "core myopathy," "centronuclear myopathy," "myosin storage myopathy," "congenital fiber-type disproportion," and "pregnancy" was undertaken in August 2017. In addition, updates of the German/ Australian series are included..$^{3,4}$ Altogether, this review incudes 21 patients with morphologically defined CM, who had a total of 29 pregnancies where clinical details were described (Table 1). For most patients, information on the underlying genetic mutation was not available, but this would not change our conclusions.

The following items were compared:

1. Clinical picture: Age at onset, first symptoms, diagnostic investigations, course of the disease, ability to walk, age when beginning to use a wheelchair, and influence of pregnancy on the course of the disease.

2. Pregnancy and delivery: Miscarriages, ectopic pregnancies, hypertensive disease, polyhydramnios, placental 


\begin{tabular}{|c|c|c|c|c|c|c|}
\hline $\begin{array}{l}\text { Morpholo-gical } \\
\text { Type }\end{array}$ & $\begin{array}{l}\text { Patient- } \\
\text { ID-Delivery No. }\end{array}$ & Onset & $\begin{array}{l}\text { Age at } \\
\text { Delivery (Y) }\end{array}$ & Pregnancy & Delivery (WG) & Newborn \\
\hline \multirow{12}{*}{$\begin{array}{l}\text { Nemaline } \\
\text { myopathy }\end{array}$} & $1-1^{5, *}$ & Infancy & 39 & $\mathbf{n}$ & Elective CS (term) & Healthy \\
\hline & $2-1^{6}$ & $6 y$ & 28 & $\mathrm{n}$ & Elective CS (term) & Healthy \\
\hline & $3-1^{6}$ & Childhood & 28 & $\mathrm{n}$ & Spontaneous & Healthy \\
\hline & $3-2^{6}$ & & 30 & $\mathrm{n}$ & Spontaneous & Healthy \\
\hline & $4-1^{6}$ & Birth & 35 & $\mathrm{n}$ & Spontaneous & Healthy \\
\hline & $5-1^{7}$ & Childhood & 30 & Respiratory compromise & Elective CS (36 WG) & Healthy \\
\hline & $6-1^{8}$ & Birth-2 y & 29 & $\begin{array}{l}\text { Hypertensive disease } \\
\text { from } 29 \mathrm{WG}\end{array}$ & $\begin{array}{l}\text { Preterm induction of labour, } \\
\text { spontaneous ( } 29 \text { WG) }\end{array}$ & $1060 \mathrm{~g}$, Apgar 6-7, retinopathy \\
\hline & $7-1^{4}$ & Birth & 28 & $\mathrm{n}$ & Elective CS (38 WG) & Healthy \\
\hline & $8-1^{4}$ & $2 y$ & 25 & $\mathrm{n}$ & Elective CS (43 WG) & Healthy \\
\hline & $9-1^{4}$ & Birth & 34 & $\mathrm{n}$ & Spontaneous (term) & Healthy \\
\hline & $10-1^{4}$ & $2 y$ & 28 & $\mathrm{n}$ & Elective CS (38 WG) & Healthy \\
\hline & 11-1 (This report) & Birth & 29 & $\mathbf{n}$ & Elective CS (37 WG) & Healthy \\
\hline \multirow[t]{11}{*}{$\begin{array}{l}\text { Central core } \\
\text { disease }\end{array}$} & $12-1^{9}$ & $3 y$ & 21 & $\mathrm{n}$ & $\begin{array}{l}\text { Elective c-section, general } \\
\text { anesthesia due to kyphoscoliosis }\end{array}$ & $\begin{array}{l}\text { Delayed adaption, Apgar 3-7-9, } \\
\text { naloxone treatment, large } \\
\text { umbilical hernia }\end{array}$ \\
\hline & $13-1^{10}$ & Birth & 19 & $\mathbf{n}$ & $\begin{array}{l}\text { Elective CS, combined } \\
\text { spinal-epidural anesthesia ( } 38 \text { WG) }\end{array}$ & Healthy \\
\hline & $14-1^{4}$ & $4 y$ & 18 & Preterm labour & Vaginal operation, preterm delivery & Healthy \\
\hline & $15-1^{4}$ & $2 y$ & 35 & $\begin{array}{l}\text { Preeclampsia } \\
\quad \text { (last trimester) }\end{array}$ & Spontaneous (term) & Healthy \\
\hline & $15-2^{4}$ & & 37 & $\mathrm{n}$ & Elective CS (term) & Affected by CCD \\
\hline & $16-1^{4}$ & $4 y$ & 32 & $\mathbf{n}$ & Spontaneous (term) & Healthy \\
\hline & $16-2^{4}$ & & 34 & $\mathrm{n}$ & Spontaneous (term) & Healthy \\
\hline & $17-1^{4}$ & $4 y$ & 23 & $\mathbf{n}$ & Spontaneous (term) & Healthy \\
\hline & $17-2^{4}$ & & 26 & $\mathrm{n}$ & Spontaneous (term) & Healthy \\
\hline & $17-3^{4}$ & & 28 & $\mathbf{n}$ & Spontaneous (term) & Affected by CCD \\
\hline & $17-4^{4}$ & & 29 & Preterm labour & Spontaneous, preterm (33 WG) & Healthy \\
\hline \multirow[t]{3}{*}{$\begin{array}{l}\text { Multi-minicore } \\
\text { disease }\end{array}$} & $18-1^{11}$ & Infancy & 25 & $\mathrm{n}$ & $\begin{array}{l}\text { Spontaneous, epidural } \\
\text { anesthesia ( } 36 \text { WG) }\end{array}$ & Healthy \\
\hline & $18-2^{12}$ & & 32 & $\mathbf{n}$ & $\begin{array}{l}\text { Spontaneous, epidural } \\
\text { anesthesia ( } 37 \text { WG) }\end{array}$ & Healthy \\
\hline & $19-1^{13}$ & Not reported & 25 & $\mathbf{n}$ & $\begin{array}{l}\text { Spontaneous, epidural } \\
\text { anesthesia (term) }\end{array}$ & Healthy \\
\hline \multirow{2}{*}{$\begin{array}{l}\text { Cytoplasmic } \\
\text { bodies }\end{array}$} & $20-1^{4}$ & $18 y$ & 27 & $\mathbf{n}$ & Vaginal operation (39 WG) & Healthy \\
\hline & $20-2^{4}$ & & 29 & & Spontaneous (term) & Healthy \\
\hline $\begin{array}{l}\text { Congenital } \\
\text { fiber-type } \\
\text { disproportion }\end{array}$ & $21-1^{4}$ & Birth & 30 & $\mathbf{n}$ & Elective CS (38 WG) & Healthy \\
\hline
\end{tabular}

disproportion

CCD, central core disease; CS, Cesarean section; $n$, normal; WG, weeks gestation; y: years.

*Previous 4 deliveries via cesarean section without further information. 
abnormalities, surgical interventions, labor abnormalities, fetal presentation, and mode of delivery.

3. Neonatal outcome: Birth measurements, Apgar scores, and general health status.

\section{Clinical Picture}

The largest group consisted of mothers with nemaline myopathy $(\mathrm{n}=11){ }^{3-8}$ followed by central core disease $(n=6),{ }^{3,4,9,10}$ and multi-minicore disease $(n=2),{ }^{11-13}$ and 1 patient each with cytoplasmic body myopathy ${ }^{4}$ and congenital fiber-type disproportion. ${ }^{4}$ Apart from one Finnish patient $^{6}$ with nemaline myopathy, who used a wheelchair from the age of 15-18 years, all other women were able to walk when becoming pregnant. The mean age at the first pregnancy was higher in nemaline myopathy (27.7 years) compared with central core/multi-minicore disease (24.8 years), but did not differ from the general population.

CMs generally have an early onset but the course of the disease is often static or disease progression is usually slow. In contrast to other neuromuscular disorders with a more pronounced progression such as limb girdle muscular dystrophy, we did not see an overall influence of pregnancy or delivery on muscle function in the German/Australian/Finnish case series. ${ }^{3,4,6}$ While we observed an impressively stable or rather improving effect of pregnancy on the well-being and physical condition in nemaline myopathy, the perception may be different in other types of CM. Among the German/Australian patients with central core disease, 2 women (14-1, 17-3, 17-4) reported a deterioration in at least 1 pregnancy. Patient 14-1 had increasing leg muscle weakness from 4 months gestation which progressed after delivery. Patient 17 developed increasing back pain based on her scoliosis in the last 2 pregnancies $(17-3,17-4)$. In the majority of other case reports, no specific evaluation of a possible influence of gestation on the disease course was undertaken. 5,8,9,11,12 Patient 19-1 with multiminicore disease reported by Klaska and Gonik ${ }^{13}$ noted ankle instability and "difficulty with ambulation" as pregnancy progressed, but seem to have normalized by 6 weeks postpartum. It has been suggested that pregnancy in nemaline myopathy be considered with caution in case of severe respiratory dysfunction, ${ }^{7}$ however, the authors of this paper did not provide further details of the rapid deterioration in their patient.

\section{Pregnancy and Delivery}

There was no evidence of an increased miscarriage or ectopic pregnancy rate in the reviewed cohort. Apart from 1 patient (6-1) with severe hypertensive disease in pregnancy from 29 weeks gestation (WG), there were no further pregnancy complications. Lung function and cardiac examinations were not systematically performed. There were 2 patients $\left(2-1,{ }^{6} 5-1^{7}\right)$ with reduced pulmonary function, but this did not result in a change of the patient's subjective condition. No woman in this review received assisted ventilation during pregnancy.

The following Case Report (patient 11-1) illustrates a typical obstetric history in nemaline myopathy.

\section{Case Report}

This woman with nemaline myopathy had first signs of the disease after birth. She had a weak cry, showed neonatal muscular hypotonia, and marked facial weakness. In the first 3 months of life, she had sucking and swallowing difficulties and required tube feeding. Her motor development was only mildly retarded: she had delayed head control but achieved the sitting position at 7-8 months, did not crawl, and walked at 14 months. Her gait was unsteady and hampered by marked weakness of the ankle dorsiflexors. She was diagnosed as having nemaline myopathy based on typical histological findings in a muscle biopsy at the age of 2 years, published previously. ${ }^{14} \mathrm{Her}$ overall condition remained remarkably stable, without progression of weakness. Her main clinical features-when last seen at age 30-were marked facial weakness, resulting in severe dysarthria, and facial dysmorphism (Fig. 1). She was unable to close her eyes or her mouth, showed a mild Gowers' sign when rising from the floor, and had a symmetric foot drop and atrophy of the interosseal hand muscles. Her mental development was normal. At age 25, she underwent a gastric bypass operation because of

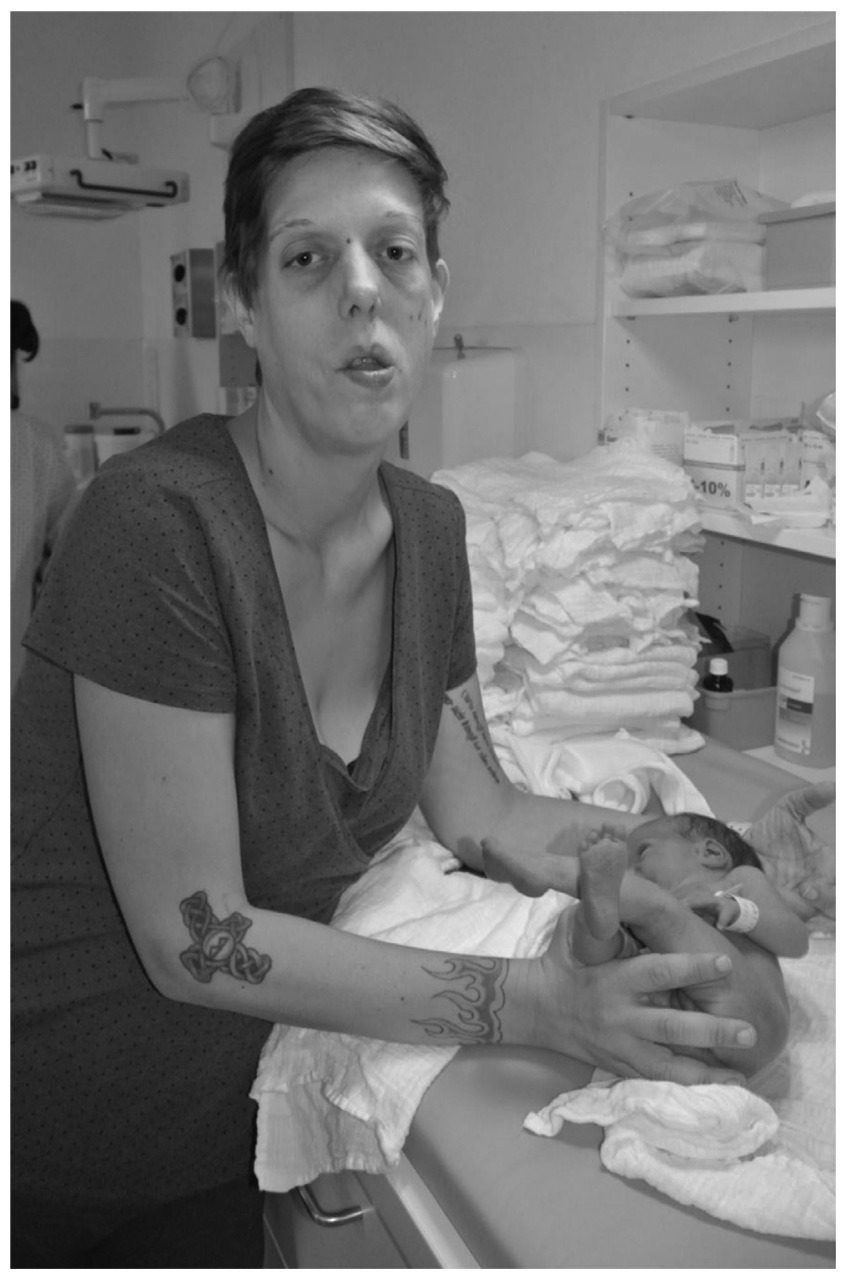

Figure 1 Patient 11-1 with congenital nemaline myopathy who delivered a healthy girl at the age of 29 years (for details, see Case Report). Note marked facial weakness. 
increasing obesity, unusual in nemaline myopathy. Her only pregnancy at age 29 was uneventful, lung function tests at $25 \mathrm{WG}$ were largely normal: forced vital capacity (FVC) 4.27 l, (98\%), FEV1 3.33 l (88\%), FEV1/FVC 78\%, maximal exspiratory flow (MEF) 50: 4.081 (89\%), normal blood gases. She delivered a healthy girl by elective Cesarean section at $36+6$ weeks. Birth measurements were normal (weight $2250 \mathrm{~g}$, length $47 \mathrm{~cm}$, head circumference $32.5 \mathrm{~cm}$ ), and the neonatal outcome was uneventful. When last seen at 18 months, the girl showed normal psychomotor development and had no signs of myopathy. The patient recovered quickly from delivery and did not experience an influence of pregnancy on her muscle functions.

In the entire study group of patients with $\mathrm{CM}$, only 3 preterm deliveries $<36 \mathrm{WG}$ (10\%) occurred, which is compatible with the rate in the general population (7\%). Most patients with onset at birth, in infancy or childhood opted for elective Cesarean section (11 of 29; 38\%), which was uneventful in 10/11 deliveries. The incidence of prolonged labor was not increased. Only 2 deliveries were completed by assisted instrumentation (vacuum extraction, forceps), thus being in line with the general population. Patients at risk for malignant hyperthermia (mostly central core or multi-minicore disease) generally received epidural anesthesia if required. One patient with central core disease and severe kyphoscoliosis (12-1) had a Cesarean section under general anesthesia. ${ }^{9}$ We found no reports of abnormal placentation or postpartum hemorrhage.

\section{Neonatal Outcome}

Neonatal outcome was favorable in children of patients with $\mathrm{CM}$ as long as the children were not affected by muscle weakness due to the same disease. Birth measurements and vital parameters were mostly normal in those infants for whom details were available. The only child of patient 6-1 with nemaline myopathy reported by Thomas and Jose $^{8}$ was born at 29 WG due to maternal hypertensive disease and had complications of prematurity. Delayed adaptation (Apgar 3-7-9) and a large umbilical hernia were observed in a newborn delivered by patient 12-1 with severe central core disease. ${ }^{9}$

\section{Personal Attitude, Coping, Practical Considerations}

Women with a congenital or early infantile onset of muscle disease will generally need help in the household and may have limited physical reserves for their tasks as a mother. When being questioned, most mothers would support the decision to have children but would seek medical advice and assistance in caring for the family.

We interviewed patient 2-1 with nemaline myopathy, who was wheelchair-dependent from $15-18$ years of age, ${ }^{6}$ according to practical considerations for women using wheelchairs who contemplate a pregnancy. These are her recommendations.

\section{Barrier-free Home}

To ensure the safety of the mother and the expected child, and to enable physical actions, it is important to consider necessary solutions to enable unrestricted movement for both mother and child inside the home. These solutions include barrier-free entrance, easy access to terrace/balcony, toilets, washbasins and showers, suitable height of table levels, as well as possible devices to simplify everyday tasks, for example, dishwasher.

\section{Personal Assistance for Your Own Needs to Maintain a Personal Reserve}

It is important to have a personal assistant because the needs caused by the disability are individual. In the beginning of the pregnancy an assistant helps sharing the responsibility of daily chores with the spouse. This is useful in order for the mother to get enough time for eating, resting, outdoor exercises, keeping up adequate muscle strength, and stretching during and after pregnancy.

Also, the help of an assistant might be needed if your bodily strength weakens due to pregnancy. After giving birth you, might need help with taking care of the baby: lifting, washing the baby etc.

More assistance will be needed if you are prohibited to lift anything due to a Cesarean section. After having had a Cesarean section, She had to use all her muscular strength for transferring herself.

\section{Early integration of help into the household}

A personal assistant makes it possible for the mother to attend also to the heavier tasks of domestic work by performing those tasks that she cannot do on her own. Also, for a wheelchair user, it might be more consuming during pregnancy to take care of normal daily household chores, and the possible nausea, fatigue, and back pain makes it even more consuming.

\section{Devices for Baby Care, for Example, a Cot Adjustable for Height, Baby Changing Unit Accessible With a Wheelchair, Baby Carriers}

An important device is a cot that moves on wheels and has adjustable height and possibly sides that can be lowered. A cot on wheels makes it easy to move the baby to the bathroom for washing and changing of diapers, although it is sometimes practical to tend to the baby on an adult-sized bed (breastfeeding, diaper changing).

A changing table, possibly with adjustable height, that is easy to access with a wheelchair is also important.

Another useful device is one that makes it possible to attach the pram to the wheelchair, thus making it possible to have both hands free for maneuvering a manual wheelchair.

A baby carrier of some sort keeps the baby safely on your lap, for instance while shopping, maneuvering the wheelchair, or during outdoor exercises.

If your child is very active, a harness is sometimes useful. 
If your own moving speed is too slow compared to the child's, it is wise to exchange your current support device for an electric wheelchair.

\section{Parental Assistance in the First Years, Spouse at Home Solutions}

During the child's first years, the help of the other parent is essential. If this is not possible, it is essential to ensure the help of a personal assistant, around the clock, if needed (eg, if you are a single mother). The help of close friends, grandparents, and close relatives is also of great importance, as it is with regular new parents, but it does not eliminate the need of an assistant.

The mother needs to be able to rest during the day if she has to be up at night with the baby. Paternity leave and parental leave should be used and these issues should be taken into account in family planning. The presence of the spouse is mentally the most important factor when it comes to family bonding.

\section{Midwives' Attendance During and After Pregnancy, Courses for Birth Preparation}

A constructive approach by the midwives and gynecologists to the pregnancy (an encouraging attitude) is important. Instead of showing prejudice against the parents-to-be, they should be able to provide the expecting mother with sufficient, personal counseling regarding possible early challenges. Lamaze class together with, for instance, a familiar physiotherapist can be helpful, and also consulting an occupational therapist, or getting useful tips from one.

\section{Home Visits by the Family Doctor or Pediatrician According to the Degree of Disability}

There are some important aspects when planning the delivery in advance: consulting a family doctor, your own GP, neurologist, gynaecologist, anaesthetist, and pediatrician during early pregnancy, as well as throughout the entire pregnancy, is important. Sticking to the agreed procedure, for example, in regard to the mode of delivery, is important. Also, if it is possible that the newborn baby can have a muscular disease, a pediatrician should be present at the delivery, and the baby's possible breathing problems taken into account.

\section{Assistance During the Hospital Stay (in Germany Possible With a New Law Regulating Paid Assistance by Personal Employment)}

The presence of an assistant during hospitalization is of great importance in order to ensure patient safety, recovery, and a quick discharge from hospital. The need for assistance is no smaller while in the hospital; rather the need for assistance grows and becomes emphasised in hospital situations.
The need for assistance also grows when the environment presents obstacles. Individual causes due to trauma, and the degree of personal help at home also affects the degree of assistance needed.

\section{Early Acquaintance With Suitable Nursery and Toddler Groups}

Easily accessible surroundings should be taken into account, as well as peer support, for example, through activities organized by the Muscular Dystrophy Associations.

\section{Support to Increase Self-respect and Self- assertion}

It is important to get information about the Muscular Dystrophy Associations and their peer support groups at an early stage. It is possible to find out about different kinds of peer support in advance; for instance, support can be found through social media.

\section{Maintain Close Relationships to Individuals Who Are Familiar With Your Needs}

Peer support, close family, and friends play an important role. It is important to be able to have confidential discussions about personal feelings, to be heard, understood, and to feel appreciated. Also, the mother's own solutions need to be respected; there are many ways of doing things.

Personal comment: If your children have a muscular disease, you should not protect them too much, but rather let them go with other children, in their ways.

\section{Positive Mentality and Trust in Your Abilities}

Recognize your own strengths and weaknesses and learn to live a rich and fulfilling life, despite possible restrictions. See the things in your life that you can do, instead of focusing on the things you cannot do. Take into account certain facts you cannot change, look for personal solutions, and make possible the things you want from your life!

\section{Comment}

Based on this review, we can conclude that the complication rate of pregnancy and delivery in CM does not differ from that of the general population. Since there are only few case reports in the medical literature, it can be assumed that many more pregnancies have gone unreported and completed without adverse effects. This can at least be delineated from larger pedigrees of autosomal dominantly inherited CM. As a precaution, the indication for elective Cesarean section is generously set. Despite the early onset of muscle weakness in CM, its progression is generally slow or stable and largely unaffected by gestation. 
With regard to anesthesia in $\mathrm{CM}$, a number of issues have to be considered. In subtypes with marked facial and neck involvement-specifically encountered in nemaline myopathy-the high-arched palate, small mouth, micro- or prognathic mandible, malocclusion, and jaw lock might complicate laryngeal intubation. ${ }^{5}$ Regional anesthesia is preferred for analgesia, but epidural blockade can be difficult in patients with severe spine deformities or surgically corrected scoliosis. 9 Precautions for deliveries at risk of malignant hyperthermia include the avoidance of volatile inhaled anesthetics and of depolarizing muscle relaxants. Vaginal delivery with early placement of an epidural catheter and use of local amide or ester anesthetics has been recommended. ${ }^{11,13}$ The preferred anesthetic is still a matter of debate; some authors advocate ropivacaine over bupivacaine in patients with muscle weakness. ${ }^{12}$ According to present knowledge, only conditions with mutations of the ryanodine receptor (RYR1) gene-causing different CM such as central core disease and subtypes of multi-minicore disease, centronuclear myopathy, and congenital fiber-type disproportion-are associated with a clearly increased risk of malignant hyperthermia. ${ }^{15}$ Therefore, genetic testing for RYR1 mutations in all patients with a potential risk for malignant hyperthermia is recommended, which is nowadays cost-efficiently achieved by massive parallel sequencing.

Pulmonary function tests may be indicated in patients with CM before contemplating pregnancy. Restrictive lung disease, respiratory muscle weakness, chest wall abnormalities, kyphoscoliosis, chronic aspiration, and infections can lead to hypoventilation which can be a major risk factor for mother and child. Despite the fact that the lower limit for vital capacity in pregnancy is illdefined, as a general rule, women with a forced vital capacity (FVC) of under 1 liter should be advised against pregnancy. ${ }^{16}$ In patients with respiratory insufficiency, the indications for assisted ventilation should not be different during pregnancy. ${ }^{17}$ Further aspects to assess are cardiac status, scoliosis, contractures including jaw lock, small mouth, neck problems, weakness of abdominal muscles, and any smooth muscle weakness.

In 2010, a workshop was organized by the European Neuromuscular Centre to give an overview of current knowledge and to summarize recommendations (Table 2) for women with neuromuscular disorders, who are or plan to become pregnant. $^{16}$ In summary, it is recommended that CM patients who wish to have children are advised by a multidisciplinary team.

Further data of obstetric histories in clinically and genetically defined subgroups would be useful in providing appropriate guidance and medical care to patients who are planning pregnancies, although sufficient data allowing for generally applicable recommendations to be made are difficult to obtain in the rare CMs.
Table 2 Recommendations to Women with CM Who Wish to Have Children, Summarized at a European Expert Meeting ${ }^{16}$

1. Preconception planning

1.1 Confirmation of diagnosis to highest level possible for prognosis of pregnancy

Comment: Provide information on current knowledge in field, including information on registries.

1.2 Genetic counselling to estimate risk to offspring

1.3 Consider and discuss reproductive options

a. Having own children without testing

b. Prenatal diagnosis

c. Preimplantation genetic diagnosis

d. Adoption

e. Gamete donation

f. Refrain from having children using suitable contraceptive measures

Comment: Consideration of referral elsewhere if additional expertise available and costs religious and cultural background.

1.4 Assessment of maternal risk factors

1. Obstetric and general history

2. Disease status

a. Functional status and change in last $5 y$

b. Skeletal deformities.

c. Bulbar function.

d. Cardiac status*

e. Respiratory status*

f. Disease-specific aspects

g. Optimization of drug treatment-(also high dose folate) Comment: *Baseline assessments according to underlying condition.

1.5 Preparation for parenthood and additional support needs

a. Role of partner

b. Family and social network

c. Logistics of childcare

d. Respite care

e. Social care: Financial, physical aids, and adaptations

f. Inform about support groups

1.6 Risk-benefit analysis

Discussion with multidisciplinary team to develop care plan. Best practice would include obstetrician (care manager), neurologist, respiratory, anesthetist, cardiac, geneticist, general medicine, or midwife as appropriate.

2. Care in each stage of pregnancy

2.1 First trimester

a. Early contact (before 10th gestational week) with obstetrician and other specialists as necessary

b. Discuss prenatal diagnosis

c. Discuss dietary intake, vitamin D supplements

d. Consider thromboprophylaxis (specifically in women using wheelchairs)

e. Consider possible teratogenicity of medication

f. Plan for fetal and maternal monitoring

2.2 Second and third trimesters

a. Consider increasing demands of pregnancy on maternal cardiac and respiratory reserve

b. Fetal anomaly scan

c. Growth scans and assessment of amniotic fluid volume

d. Awareness of conditions leading to preterm labor

e. Gastro-esophageal reflux treatment 
f. Management of other non-neuromuscular disorder (NMD) complications, eg, caution with magnesium sulphate use in preeclampsia

g. Plan for delivery: Location, mode, anesthesia, fetal presentation

2.3 Labor and delivery

1. Spontaneous vaginal delivery

a. Induction of labor

b. Consider shortened second stage and assisted vaginal delivery

2. Elective cesarean section

a. Operative technique and positioning

b. Presence of team, including neonatologist

c. Choice and dosing of analgesia

d. Anesthetic issues: Regional or general, airway access, spinal deformity, risk of malignant hyperthermia or other adverse effects of anesthetic agents

e. Active management of third stage to prevent postpartum hemorrhage and measure blood loss.

3. Postpartum period

a. Monitoring for deterioration-level 2 environment

b. Physical assistance for mother with care for baby and breastfeeding

c. Monitoring of baby if appropriate

d. Consider longer inpatient stay

e. Continuing contact with same midwife or other health professionals.

4. Specific recommendations

4.1 Respiratory disease

a. Define high risk groups: Diaphragm involvement

b. Baseline respiratory review

c. Baseline measurements

d. Forced vital capacity $<\mathbf{5 0} \%$ predicted (or $1 \mathrm{~L}$ ), maximum inspiratory pressure $<60 \mathrm{~cm} \mathrm{H} 2 \mathrm{O}$, peak cough flow $<160 \mathrm{~L} / \mathrm{min}$ measured at baseline and in each trimester should prompt the physician to undertake an arterial blood gas sample and respiratory sleep study e. Mode of delivery planned in multidisciplinary team

f. Early epidural analgesia

g. Low dose opiate analgesia

h. Continuous transcutaneous carbon dioxide monitoring in level 2 area to continue postpartum

i. For those established on noninvasive ventilation, continue as before.

4.2 Cardiac disease

a. The potential impact of pregnancy on heart condition should be discussed well in advance for patients with NMDs at risk for cardiac disease

b. The risk for cardiac complications should be evaluated (high: New York Heart Association (NYHA) class III-IV, ejection fraction $<45 \%$, prior history, or stroke or arrhythmia; intermediate: NYHA class II or ejection fraction $45 \%-60 \%$ )

c. Continuous cardiac monitoring in level 2 area

d. Avoid angiotensin converting enzyme (ACE) inhibitors

and angiotensin receptor blockers

e. Cardiac follow-up should include an echocardiogram at least each month if ejection fraction is $<45 \%$ and each trimester if $45 \%-60 \%$

f. In patients with a prior history of sustained arrhythmia or palpitations, Holter-electrocardiogram (ECG) should be considered g. Labor and delivery time should be as short as possible h. Vaginal delivery contraindicated in those with decompensated cardiac disease

i. Continuous epidural analgesia to reduce pain-related heart rate increase

j. Avoid oxytocin bolus due to risk of tachycardia.

\section{References}

1. North KN, Wang CH, Clarke N, et al: Approach to the diagnosis of congenital myopathies. Neuromuscul Disord 224:97-116, 2014

2. Norwood FL, Harling C, Chinnery PF, et al: Prevalence of genetic muscle disease in Northern England: In-depth analysis of a muscle clinic population. Brain 132:3175-3186, 2009

3. Rudnik-Schöneborn S, Glauner B, Röhrig D, et al: Obstetric aspects in women with facioscapulohumeral muscular dystrophy, limb-girdle muscular dystrophy, and congenital myopathies. Arch Neurol 54:888-894, 1997

4. Awater C, Zerres K, Rudnik-Schöneborn S: Pregnancy course and outcome in women with hereditary neuromuscular disorders: Comparison of obstetric risks in 178 patients. Eur J Obstet Gynecol Reprod Biol 162:153-159, 2012

5. Stackhouse R, Chelmow D, Dattel BJ: Anesthetic complications in a pregnant patient with nemaline myopathy. Anesth Analg 79:1195-1197, 1994

6. Wallgren-Pettersson C, Hiilesmaa VK, Paatero H: Pregnancy and delivery in congenital nemaline myopathy. Acta Obstet Gynecol Scand 94:659-661, 1995

7. Eskandar OS, Eckford SD: Pregnancy in a patient with nemaline myopathy. Obstet Gynecol 109:501-504, 2007

8. Thomas V, Jose R: Nemaline myopathy and pregnancy: A challenge indeed. Neurol India 60:524-525, 2012

9. Foster RN, Boothroyd KP: Caesarean section in a complicated case of central core disease. Anaesthesia 63:544-547, 2008

10. Waikar PV, Wadsworth R: A patient with severe central core disease. $\mathrm{Br}$ J Anaesth 101:284, 2008

11. Osada H, Masuda K, Seki K, et al: Multi-minicore disease with susceptibility to malignant hyperthermia in pregnancy. Gynecol Obstet Invest $58: 32-35,2004$

12. Saito O, Yamamoto T, Mizuno Y: Epidural anesthetic management using ropivacaine in a parturient with multi-minicore disease and susceptibility to malignant hyperthermia. J Anesth 21:113, 2007

13. Klaska C, Gonik B: Obstetric outcome in a primigravid patient with autosomal recessive multiminicore myopathy. Obstet Gynecol 123:438-440, 2014

14. Dózy LC, Morscher R, Schmitzberger R, et al: Nemaline-myopathie: Ein besonderer Verlauf. Padiatr Padol 26:49-51, 1991

15. Brislin RP, Theroux MC: Core myopathies and malignant hyperthermia susceptibility: A review. Pediatric Anesthesia 23:834-841, 2013

16. Norwood F, Rudnik-Schöneborn S: 179th ENMC international workshop: Pregnancy in women with neuromuscular disorders. 5-7 November 2010, Naarden, The Netherlands. Neuromuscul Disord 22:183-190, 2012

17. Gamzu R, Shenhav M, Fainaru O, et al: Impact of pregnancy on respiratory capacity in women with muscular dystrophy and kyphoscoliosis. J Reprod Med 47:53-56, 2002 